\title{
Comparison of the Effects of Physiotherapy Group Exercise and Basketball on Quality of Life of Obese Children
}

\author{
Zehra Güçhan Topcu ${ }^{*}$, Özlem Ülger² \\ ${ }^{1}$ Department of Physiotherapy and Rehabilitation, Faculty of Health Sciences, Eastern Mediterranean University, Famagusta, \\ Cyprus \\ ${ }^{2}$ Department of Physiotherapy and Rehabilitation, Faculty of Health Sciences, Hacettepe University, Ankara, Turkey \\ Email: *zehra.guchan@emu.edu.tr
}

How to cite this paper: Topcu, Z.G. and Ülger, Ö. (2017) Comparison of the Effects of Physiotherapy Group Exercise and Basketball on Quality of Life of Obese Children. Open Journal of Therapy and Rehabilitation, 5, 1-10.

https://doi.org/10.4236/ojtr.2017.51001

Received: November 7, 2016

Accepted: January 2, 2017

Published: January 5, 2017

Copyright $\odot 2017$ by authors and Scientific Research Publishing Inc. This work is licensed under the Creative Commons Attribution International License (CC BY 4.0).

http://creativecommons.org/licenses/by/4.0/

\begin{abstract}
Aim: To compare the effects of group exercises under physiotherapist control and basketball program on the quality of life of obese children. Methods: 45 obese children aged 10 years were randomly included to the physiotherapy ( $\mathrm{n}$ =14), basketball (n: 15), and control group ( $n: 16)$. The children were assessed before and after 12-week study duration. The Pediatric Quality of Life Inventory (PedsQL) was used to determine and compare their quality of life (QoL). Results: No difference was found when the subheadings of the PedsQL were compared among the groups ( $\mathrm{p}>0.05)$. When the changes were investigated within the groups, only significant increase was determined in the physical and emotional subheadings of the physiotherapy group $(\mathrm{p}<0.05)$. Conclusion: Although no change was determined in the quality of life, physiotherapy group exercise was found to be more successful to affect physical and emotional status of obese children.
\end{abstract}

\section{Keywords}

Physiotherapy, Basketball, Quality of Life, Obese Children

\section{Introduction}

Obesity is one of the most important health problems in both developing and developed countries [1] [2]. Prevalence of obesity, particularly in children and adolescents, has gradually increased in recent years [2] [3] [4].

Excess of weight leads to more stress on musculoskeletal system and this causes both musculoskeletal injuries and postural deformities [5] [6]. Motor performances of children are also negatively affected by excess weight [7]. In- 
adequate physical activity of overweight children leads to impaired postural control so more extremity injuries and more fractures are observed in this population [8] [9] [10]. As a result of these issues, overweight and obese children have lower level of health related QoL than their peers with normal weight [11].

Within the obesity treatment, planning a diet program and increasing physical activity are the basic approaches. Inactive life in childhood may cause various problems like obesity and cardiovasculary diseases. A new diagnosis called "Exercise-Deficit Disorder" has been generated to emphasize this life style [12]. Participating in physical activity alone will not be a sufficient intervention to prevent or treat childhood obesity. However, it may support weight loss and decrease cardiovasculary risk in the case of obesity [13] [14].

When the roles of physiotherapists in managing childhood obesity are investigated, they treat the pain developing from musculoskeletal system of obese children, try to prevent postural problems and plan effective exercise programs [15]. Doing regular exercise contributes to treat childhood obesity and to solve the problems coming from obesity such as, musculoskeletal problems and low level of QoL [16] [17].

Group exercises had positive effects on metabolic risks and cardiorespiratory fitness of obese children. Moreover, when group exercise was conducted accompanied with the music, children were found to be more physically active [18].

Furthermore, Kuni et al. stated that postural control of overweight children was improved by the combination of ball games and diet program [8]. Among many team sport branches, basketball can be popularly played by both genders and various motor skills like endurance, strength and speed can be improved by playing it [19] [20]. Elsayed (2014) included 12 obese and overweight children in basketball group and included 12 peers in control group and revealed that body composition and motor skills significantly increased in the basketball group, while no change was determined in their control group [21]. They did not investigate the effects of basketball on QoL of these children.

The roles of active physiotherapy programs and sport programs on the management of the problems arising from childhood obesity should be determined. Although the effects of exercise and various sport branches on decrease obesity and obesity related problems were discussed, the effects of group exercises managed by physiotherapists and team sports on QoL of obese children are not clear. This study aims to compare the effects of physiotherapy group exercise and basketball education on the level of QoL of these children.

\section{Materials and Methods}

\subsection{Subjects}

Six primary state schools which were close to the research area were included to provide regular participation of all children. The parents and their childen aged 10 years old were asked to permit the height and weight measurements. After the Body Mass Index values were obtained, 81 children were found to be adequate to 
be invited.

The inclusion criteria were as follows (1) children who were born in 2006, (2) children whose BMI values were $\geq 95$. Percentiles, (3) a report which was given by a doctor states that the child could participate in aerobic exercise, (4) children who had not continued to a diet program for 3 months, (5) children who had not participated regularly in any sport or exercise for 6 months. The children who had any disease requiring use of medicine, who had any pain preventing doing exercise or sport, and who had any neuromuscular disease were excluded from the study. A flowchart of the participation of children in the study is shown in Figure 1.

45 children ( 25 girls, 20 boys) were found to be appropriate to participate in the study and were assessed in the same week. Informed consent approved by the Hacettepe University Ethical Committee (registration number GO 16/53) was obtained from both the child and the parents of each child. Following the first assessments, children were randomly distributed to the physiotherapy group, basketball group, and control group.

During the 12-week intervention, one child from the physiotherapy and two children from the basketball left the programs because of their intensive school program. Therefore, 13 children in each group completed the intervention duration and 42 children, in total, were reassessed in the end of 12 weeks.

\subsection{Methods}

Demographic characteristics of children and information about using the technological devices were recorded.

Health related QoL of the children were assessed using the PedsQL-Child Form [22]. The inventory has 23 items and its subheadings are physical health, emotional functioning, social functioning, and school functioning. The score ranges from 0 to 100 and high scores indicate the high level of QoL [22]. Its Turkish reliability and validity were shown in the study by Memik et al [22]. The questionnaire was translated by three investigators and the internal reliability of the physical health, emotional functioning, social functioning, and school functioning subheadings was $r=0.737, r=0.687, r=0.663$, and $r=0.591$, respectively.

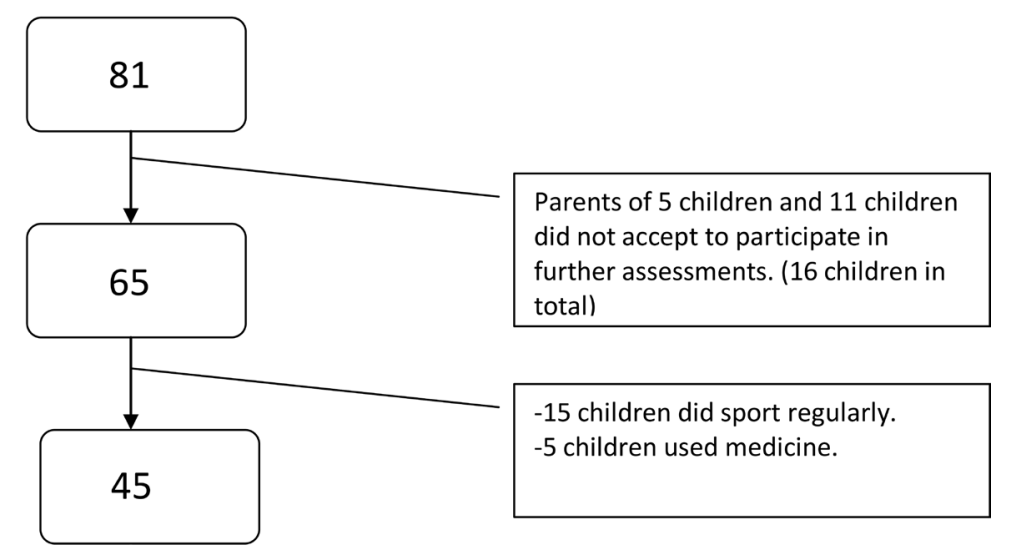

Figure 1. The flowchart of children's participation. 
The physiotherapy group exercises and basketball program continued 12 weeks [16]. Both interventions continued 60 minutes, 3 times a week. "Participation Certificates" were presented in randomly chosen intervention day of every week to children in order to motivate their participation in their physical activity.

\subsection{Group Exercise Program Accompanied by Physiotherapist}

Theraband and exercise mat were used as materials in the exercises. The colors of the therabands changed every four week. "Yellow" was the beginning theraband and used in the first four weeks. "Red" theraband was used during $4-8$ weeks and "green" was the color of theraband during last four weeks. Repetition numbers of exercises were $8-10$ in the first four weeks and were then increased to 12 - 15. Exercises were conducted accompanying with the music.

In the first 15 minute, children were asked to move their shoulders, knees, fingers, feet and to jogging in place, jumping like shooting a basket to motivate aerobic activity. The songs like "shoulder-knees and toes" were chosen for the beginning exercises. Then, the second part of the group exercise session lasted 35 minutes. The gastrocnemius and quadriceps femoris muscles were stretched. Various standing positions like Tandem or single leg were used to improve balance. After standing position, children were asked to take their personal mats and therabands and body weight were used to strength muscles. At the end of the session, children were asked to stretch the muscles of columna vertebralis, neck muscles and lumbar extansors, and to do breathing exercises so cooling down was provided during 10 minutes.

\subsection{Basketball Education}

Basketball education was given to the children by a specialist trainer. Basketball trainer created the program by using the literature related to obese children [21].

10 minute running and stretching were conducted for both warming and cooling in the beginning and ending of every session. Pass Exercises, Dribble exercises, Defence, Stopping exercises, Shot exercises, Weave, Drill, Fast Break, Attack exercises, and Game were taught to the children.

\subsection{Control Group}

16 obese children who did not participate in any physical activity during 12 weeks were included in the control group and they were assessed before and after 12 weeks

\section{Statistical Analysis}

SPSS 19 statistical software package (IBM SPSS Statistics 19, SPSS inc., an IBM Co., Somers, NY) was used for statistical analysis. Difference at $\mathrm{p}<0.05$ level was considered to be statistically significant. Mean \pm Standard Deviation $(\mathrm{X} \pm$ SD) was used to indicate the continuous variables acquired by the measurements. Percentage (\%) was calculated to indicate the descriptive variables. Since the data 
was normally distributed, One Way Variance Analysis was used to compare the variables among groups. Dependent $t$ test was also conducted to compare the results within the groups over time.

\section{Findings}

45 children participated in the study. The groups were not homogeny according to the gender $(\mathrm{p}<0.05)$. No significant difference was found in the technological use of the children ( $\mathrm{p}>0.05$ ) (Table 1 ). 34 of 45 children regularly used technological devices and most of them used them to play game and follow social media.

The BMI values were calculated as $25.83 \pm 2.76 \mathrm{~kg} / \mathrm{m}^{2}$ in physiotherapy group, $25.05 \pm 2.77 \mathrm{~kg} / \mathrm{m}^{2}$ in basketball group, and $25.12 \pm 2.79 \mathrm{~kg} / \mathrm{m}^{2}$ in control group. The groups were found to be homogeny with these beginning values $(\mathrm{p}=0.708)$.

Table 2 shows the beginning scores of the quality of life of children which were similar among groups $(\mathrm{p}>0.05)$. The lowest scores were acquired from the "emotional functioning" subheading of all groups.

When the results were observed within groups following 12-week intervention, there was significant increases in the physical health $(\mathrm{p}=0.001)$ and emotional functioning $(\mathrm{p}=0.007)$ subheadings of the PedsQL in the group of physiotherapy (Table 3). Except this result, no significant changes were found in both basketball and control groups ( $p>0.05$ ) (Table 3 ). The children in the basketball group had slight decreases in the physical health, emotional functioning and school functioning, whereas there was a slight decrease in physical health of children of the control group.

When the groups were compared following 12 weeks, no difference was found in any subheading of PedsQL ( $\mathrm{p}>0.05$ ) (Table 4).

Table 1. Sociodemographic information of the groups.

\begin{tabular}{cccccc}
\hline & & $\begin{array}{c}\text { Physiotherapy } \\
(\mathrm{n}=14) \mathrm{n}(\%)\end{array}$ & $\begin{array}{c}\text { Basketball } \\
(\mathrm{n}=15) \mathrm{n}(\%)\end{array}$ & $\begin{array}{c}\text { Control } \\
(\mathrm{n}=16) \mathrm{n}(\%)\end{array}$ & $\mathrm{p}$ \\
\hline \multirow{2}{*}{ Gender } & Girl & $11(44)$ & $4(16)$ & $10(40)$ & $\mathbf{0 . 0 1 3}$ \\
& Boy & $3(15)$ & $11(55)$ & $6(30)$ & \\
\multirow{2}{\text{Technological}}{$\begin{array}{c}\text { Use } \\
\text { Yes }\end{array}$} & No & $2(35,29)$ & $10(29,41)$ & $12(35,29)$ & $\mathbf{0 . 4 9 0}$ \\
\hline
\end{tabular}

Table 2. Comparison of the quality of life of the groups before 12 weeks.

\begin{tabular}{ccccr}
\hline & $\begin{array}{c}\text { Physiotherapy } \\
(\mathbf{n}=14) \bar{x} \pm S\end{array}$ & $\begin{array}{c}\text { Basketball } \\
(\mathbf{n}=15)\end{array}$ & \multicolumn{2}{c}{ Control } \\
& $77.23 \pm 11.06$ & $77.5 \pm 21.27$ & $81.06 \pm 10.79$ & 0.739 \\
Physical Health & $65.71 \pm 17.85$ & $76 \pm 19.38$ & $72.5 \pm 13.04$ & 0.262 \\
Emotional Functioning & $82.86 \pm 13.69$ & $78.33 \pm 24.4$ & $80.94 \pm 15.62$ & 0.805 \\
Social Functioning & $80 \pm 11.6$ & $77.67 \pm 20.78$ & $77.5 \pm 16.23$ & 0.904 \\
School Functioning & & & &
\end{tabular}


Table 3. Comparison of the quality of life within the groups before and after 12 weeks.

\begin{tabular}{|c|c|c|c|}
\hline & \multicolumn{2}{|c|}{ Physiotherapy $(n=13)$} & \multirow{2}{*}{$\mathrm{p}$} \\
\hline & Before & After & \\
\hline Physical Health & $77.89 \pm 11.23$ & $85.82 \pm 11.17$ & 0.001 \\
\hline Emotional Functioning & $66.92 \pm 17.97$ & $76.15 \pm 15.3$ & 0.007 \\
\hline Social Functioning & $82.31 \pm 14.09$ & $85.38 \pm 13.46$ & 0.337 \\
\hline \multirow[t]{3}{*}{ School Functioning } & $78.85 \pm 11.21$ & $77.31 \pm 10.92$ & 0.625 \\
\hline & \multicolumn{2}{|c|}{ Basketball $(n=13)$} & \multirow{2}{*}{$\mathrm{p}$} \\
\hline & Before & After & \\
\hline Physical Health & $77.64 \pm 22.24$ & $69.71 \pm 22.07$ & 0.348 \\
\hline Emotional Functioning & $76.15 \pm 20.02$ & $73.85 \pm 15.16$ & 0.735 \\
\hline Social Functioning & $78.08 \pm 25.04$ & $80.77 \pm 22.62$ & 0.687 \\
\hline \multirow[t]{3}{*}{ School Functioning } & $78.08 \pm 22.04$ & $76.92 \pm 15.21$ & 0.825 \\
\hline & \multicolumn{2}{|c|}{ Control $(n=16)$} & \multirow{2}{*}{$\mathrm{p}$} \\
\hline & Before & After & \\
\hline Physical Health & $81.06 \pm 10.79$ & $80.28 \pm 14.95$ & 0.760 \\
\hline Emotional Functioning & $72.5 \pm 13.04$ & $75.94 \pm 16.15$ & 0.278 \\
\hline Social Functioning & $80.94 \pm 15.62$ & $83.44 \pm 15.89$ & 0.204 \\
\hline School Functioning & $77.5 \pm 16.23$ & $78.75 \pm 17.94$ & 0.657 \\
\hline
\end{tabular}

Table 4. Comparison of the quality of life of the groups after 12 weeks.

\begin{tabular}{ccccc}
\hline & $\begin{array}{c}\text { Physiotherapy }(\mathbf{n}=13) \\
\bar{x} \pm S\end{array}$ & $\begin{array}{c}\text { Basketball }(\mathbf{n}=13) \\
\bar{x} \pm S\end{array}$ & $\begin{array}{c}\text { Control }(\mathbf{n}=16) \\
\bar{x} \pm S\end{array}$ & $\mathbf{p}$ \\
\hline Physical Health & $85.82 \pm 11.17$ & $69.71 \pm 22.07$ & $80.28 \pm 14.95$ & 0.052 \\
Emotional Functioning & $76.15 \pm 15.3$ & $73.85 \pm 15.16$ & $75.94 \pm 16.15$ & 0.915 \\
Social Functioning & $85.38 \pm 13.46$ & $80.77 \pm 22.62$ & $83.44 \pm 15.89$ & 0.799 \\
School Functioning & $77.31 \pm 10.92$ & $76.92 \pm 15.21$ & $78.75 \pm 17.94$ & 0.943 \\
\hline
\end{tabular}

\section{Discussion}

The parents of overweight and obese children were asked to motivate their children be more physically active, but no adequate information about the most appropriate physical activity was presented to them. This study aimed to determine more effective physical activity in order to increase quality of life in childhood obesity. The impacts of physiotherapy group exercises and basketball as a sport branch on quality of life of obese children were compared. Although no significant difference was found among groups, the children who participated in the physiotherapy group perceived themselves to be at higher levels of physical health and emotional functioning following 12 weeks.

The intervention programs have continued for 12 weeks. Duration of physical activity ranges from 6 weeks to a year in the literature, but in the review by Kel- 
ley et al., the effects of exercise programs were investigated in 12 weeks [16]. Physiotherapy was presented in a group concept as Basketball is a team game. Moreover, various authors compared the effects of group based and individual based physiotherapy on the patients with similar diagnosis [23] [24] [25]. Both programs were found to be effective, but in some, group exercises had more effects and more cost efficiency. Although studies which investigated the effects of group exercises in obesity were found, physiotherapists did not manage these exercises [18] [26]. Byun and Lee included 14 obese children in group exercise and 14 obese children in control group, but the details of their methods were not explained [18]. Thus, as far as we know, this study is the first paper investigating the effects of group based exercise which was controlled by a physiotherapist on obese population.

Age is an important factor which may affect many variables related to body composition so we wanted to eliminate the changes about this and children aged 10 years old were only involved. The other reason to choose the 10 years of age can be explained that according to the Gallahue's motor development model, children aged 7 - 10 years old are asked to experience every type of sport branch to determine the most appropriate one for them before the specialized stage which covers 11 - 14 years of age [27].

Most of the children used technology to play games or to communicate with others. Vandewater et al. stated that time spent on sedantery activities like watching TV causes childhood obesity [28]. Bhadoria et al. compared the time spent on technology of 451 obese and 451 non-obese children and found that obese children used technology for significantly longer durations [29]. Achievement of an appropriate use of technology among children is an essential factor to both prevent from obesity and treat obesity [30]. Thus, our findings also indicated that the parents of obese children should be more carefull to provide the correct use of technology of their children.

Simon et al. [11] indicated low level of health related QoL of obese children and stated the reason as poor body compositon, seconder health problems, and bad feelings as emotional. According to Memik et al. [22], healthy children averagely had 80 from every subheading of the PedsQL. Thus, similar to Simon et al., the children of this study had lower level of QoL from the healthy children, particulariy in the physical health, emotional functioning and school functioning subheadings.

The "physical health" and "emotional functioning" subheadings of the PedsQL significantly improved in the physiotherapy group. Except this, there was no change when the differences between before and after 12 weeks were investigated within the groups or when the findings of the groups were compared following 12 weeks. This result shows that physiotherapy which supports mobility of children increased the physical health parameter of QoL of obese children. In addition, exercises were practiced with the music and children did not feel any competition during exercise. On the other hand, some difficulties were observed during the sessions of Basketball as some children reported that their friends did 
not throw the ball to them so several issues sharing and competitive issues arised. Thus, trainers should be aware of the psychology of overweight or obese children and try to motivate them continue participating in sport. Vella et al. stated that the parents of obese children who regularly do sport perceived higher level of QoL of their children than the parents of obese children who are physically inactive [31]. Although no randomized controlled study investigated the effects of doing physical activity on the QoL, Bock et al. presented a one year multidisciplinary program including diet, physical activity, and psychological support to obese children and revealed that the same improved subheadings of the QoL to our physiotherapy group increased following this period [32]. In addition, PedsQL may be inadequate to reveal all effects of physiotherapy and basketball on the population of obese children. A specific QoL questionnaire to them may be developed in future.

To our knowledge, this is the first paper which compares the effects of physiotherapy and a sport branch on children with obesity. However, there are some limitations of this study. Gender distribution of the groups was not homogeny and the sample size was small. Homogen groups with larger sample sizes could reveal more accurate results.

\section{Conclusion}

Physiotherapy exercises may increase quality of life of obese children. In conclusion, physiotherapists should be more active while choosing appropriate sport branch and also presenting physiotherapy exercises for an obese child to improve the quality of life.

\section{Acknowledgements}

We thank to Arkan Arşehit as he managed the basketball education of children.

\section{References}

[1] Wadden, A.T. and Stunkard, J.A. (2003) Obezite Tedavi El Kitabı Türkçesi, 1. Baskı, And yayıncılık, İstanbul,.

[2] Jiménez-Ormeño, E., Aguado, X., Delgado-Abellán, L., Mecerreyes, L. and Alegre, L.M. (2013) Foot Morphology in Normal-Weight, Overweight, and Obese Schoolchildren. European Journal of Pediatrics, 172, 645-652. https://doi.org/10.1007/s00431-013-1944-4

[3] Williams, E.P., Mesidor, M., Winters, K., Dubbert, P.M. and Wyatt, S.B. (2015) Overweight and Obesity: Prevalence, Consequences, and Causes of a Growing Public Health Problem. Current Obesity Reports, 4, 363-370. https://doi.org/10.1007/s13679-015-0169-4

[4] D’Hondt, E., Deforche, B., De Bourdeaudhuij, I. and Lenoir, M. (2008) Childhood Obesity Affects Fine Motor Skill Performance under Different Postural Constraints. Neuroscience Letters, 440, 72-75. https://doi.org/10.1016/j.neulet.2008.05.056

[5] Daniels, S.R. (2009) Complications of Obesity in Children and Adolescents. International Journal of Obesity, 33, S60-S65. https://doi.org/10.1038/ijo.2009.20

[6] Batistão, M.V., Carnaz, L., Barbosa, L.F., Motta, G.C.D. and Sato, T.D.O. (2014) 
Posture and Musculoskeletal Pain in Eutrophic, Overweighed, and Obese Students. A Cross-Sectional Study. Motriz. Revista de Educação Física, 20, 192-199. https://doi.org/10.1590/S1980-65742014000200009

[7] Vameghi, R., Shams, A. and Dehkordi, P.S. (2013) The Effect of Age, Sex and Obesity on Fundamental Motor skills among 4 to 6 Years-Old Children. Pakistan Journal of Medical Sciences, 29, 586. https://doi.org/10.12669/pjms.292.3069

[8] Kuni, B., Rühling, N.E., Hegar, U., Roth, C. and Schmitt, H. (2015) Ball Games and Nutrition Counseling İmprove Postural Control in Overweight Children. BMC Pediatrics, 15, 205. https://doi.org/10.1186/s12887-015-0523-4

[9] Pomerantz, W.J., Timm, N.L. and Gittelman, M.A. (2010) Injury Patterns in Obese versus Nonobese Children Presenting to a Pediatric Emergency Department. Pediatrics, 125, 681-685. https://doi.org/10.1542/peds.2009-2367

[10] Valerio, G., Gallè, F., Mancusi, C., Di Onofrio, V., Guida, P., Tramontano, A., et al. (2012) Prevalence of Overweight in Children with Bone Fractures: A Case Control Study. BMC Pediatrics, 12, 1. https://doi.org/10.1186/1471-2431-12-166

[11] Simon, A.E., Chan, K.S. and Forrest, C.B. (2008) Assessment of Children's Health-Related Quality of Life in the United States with a Multidimensional Index. Pediatrics, 121, 118-126. https://doi.org/10.1542/peds.2007-0480

[12] Stracciolini, A., Myer, G.D. and Faigenbaum, A.D. (2013) Exercise-Deficit Disorder in Children: Are We Ready to Make This Diagnosis? The Physician and Sportsmedicine, 41, 94-101. https://doi.org/10.3810/psm.2013.02.2003

[13] Nelson, T.F. (2016) Sport and the Childhood Obesity Epidemic. In: Messner, M.A. and Musto, M., Eds., Child s Play: Sport in Kids Worlds, Rutgers University Press, New Brunswick, 82.

[14] Hansen, P.R., Andersen, L.J., Rebelo, A.N., Brito, J., Hornstrup, T., Schmidt, J.F., et al. (2013) Cardiovascular Effects of 3 Months of Football Training in Overweight Children Examined by Comprehensive Echocardiography: A Pilot Study. Journal of Sports Sciences, 31, 1432-1440. https://doi.org/10.1080/02640414.2013.792951

[15] You, L., Sadler, G., Majumdar, S., Burnett, D. and Evans, C. (2012) Physiotherapists' Perceptions of Their Role in the Rehabilitation Management of Individuals with Obesity. Physiotherapy Canada, 64, 168-175. https://doi.org/10.3138/ptc.2011-01

[16] Kelley, G.A., Kelley, K.S. and Pate, R.R. (2015) Exercise and BMI in Overweight and Obese Children and Adolescents: A Systematic Review and Trial Sequential Meta-Analysis. BioMed Research International, 2015, Article ID: 704539. https://doi.org/10.1155/2015/704539

[17] Blüher, S., Panagiotou, G., Petroff, D., Markert, J., Wagner, A., Klemm, T., et al. (2014) Effects of a 1-Year Exercise and Lifestyle Intervention on Irisin, Adipokines, and Inflammatory Markers in Obese Children. Obesity, 22, 1701-1708. https://doi.org/10.1002/oby.20739

[18] Byun, J.G. and Lee, P.Y. (2012) Effects of Group Exercise Program on Neuroplacidity and Metabolic Risk Factors in Obesity Children. International Journal of Human Movement Science, 6, 153-165.

[19] Gaca, A.M. (2009) Basketball Injuries in Children. Pediatric Radiology, 39, 12751285. https://doi.org/10.1007/s00247-009-1360-0

[20] Kalkavan, A., Pınar, A., Kılınç, F. and Yüksel, Y. (2005) Basketbolcu çocukların fiziksel yapılarının, bazı fizyolojik ve biyomotorik özellikler üzerine etkisinin araştırılması. The Research into the Effects of Child Basketball.

[21] Elsayed, T.A. (2014) Eight Weeks of Basketball Practice Can Significantly Alter Body Composition and Motor Proficiency in Primary School Children Who Are 
Overweight. Journal of American Science, 10, 212-220.

[22] Memik, N.Ç., Ağaoğlu, B., Coşkun, A. and Karakaya, I. (2008) The Validity and Reliability of Pediatric Quality of Life İnventory in 8-12 Year Old Turkish Children. Çocuk ve Gençlik Ruh Sağlı̆̆ı Dergisil Turkish Journal of Child and Adolescent Mental Health, 15, 87-98.

[23] Sokunbi, G., Gambo, H.B. and Blasu, C. (2015) Effects of Group-Based versus Individual-Based Spinal Stability Exercises (SSE) on Physical Health and Mental Wellbeing of Patients with Chronic Low Back Pain (LBP): A Randomized Controlled Trial (RCT). Journal of Pain \& Relief, 4, Article ID: 1000203.

[24] Demain, S., Smith, J.F., Hiller, L. and Dziedzic, K. (2001) Comparison of Group and Individual Physiotherapy for Female Urinary Incontinence in Primary Care: Pilot Study. Physiotherapy, 87, 235-242. https://doi.org/10.1016/S0031-9406(05)60784-5

[25] O’Keeffe, M., Hayes, A., McCreesh, K., Purtill, H. and O’Sullivan, K. (2016) Are Group-Based and Individual Physiotherapy Exercise Programmes Equally Effective for Musculoskeletal Conditions? A Systematic Review and Meta-Analysis. British Journal of Sports Medicine. https://doi.org/10.1136/bjsports-2015-095410

[26] Deusinger, S. and Burlis, T. (2008) Promoting Health and Fitness for Obese Adults via Group Exercise Formats. Cardiopulmonary Physical Therapy Journal, 19, 142.

[27] Gallahue, D.L. (1982) Understanding Motor Development in Children. John Wiley $\&$ Sons, Hoboken.

[28] Vandewater, E.A., Shim, M.S. and Caplovitz, A.G. (2004) Linking Obesity and Activity Level with Children's Television and Video Game Use. Journal of Adolescence, 27, 71-85. https://doi.org/10.1016/j.adolescence.2003.10.003

[29] Bhadoria, A.S., Kapil, U. and Kaur, S. (2015) Association of Duration of Time Spent on Television, Computer and Video Games with Obesity amongst Children in National Capital Territory of Delhi. International Journal of Preventive Medicine, 6 , 80.

[30] Durant, N.H. (2010) Not Just Fun and Games: Harnessing Technology to Address Childhood Obesity. Childhood Obesity, 6, 283-284. https://doi.org/10.1089/chi.2010.0512

[31] Vella, S.A., Cliff, D.P., Magee, C.A. and Okely, A.D. (2014) Sports Participation and Parent-Reported Health-Related Quality of Life in Children: Longitudinal Associations. The Journal of Pediatrics, 164, 1469-1474. https://doi.org/10.1016/j.jpeds.2014.01.071

[32] Bock, D.E., Robinson, T., Seabrook, J.A., Rombeek, M., Norozi, K., Filler, G., et al. (2014) The Health Initiative Program for Kids (HIP Kids): Effects of a 1-Year Multidisciplinary Lifestyle Intervention on Adiposity and Quality of Life in Obese Children and Adolescents-A Longitudinal Pilot Intervention Study. BMC Pediatrics, 14, 296. https://doi.org/10.1186/s12887-014-0296-1 
Submit or recommend next manuscript to SCIRP and we will provide best service for you:

Accepting pre-submission inquiries through Email, Facebook, LinkedIn, Twitter, etc. A wide selection of journals (inclusive of 9 subjects, more than 200 journals)

Providing 24-hour high-quality service

User-friendly online submission system

Fair and swift peer-review system

Efficient typesetting and proofreading procedure

Display of the result of downloads and visits, as well as the number of cited articles Maximum dissemination of your research work

Submit your manuscript at: http://papersubmission.scirp.org/

Or contact ojtr@scirp.org 